\title{
EDITORIAL
}

\section{Requisite for stringent control of oxygen therapy in the neonatal period}

\author{
B. Fauroux and A. Clément
}

B rief administrations of oxygen are commonly given to term and premature newborns after delivery or before invasive procedures to prevent hypoxaemia. But, to date, no study has validated the usefulness and innocuity of this pre-oxygenation method. Now, in the current issue of the European Respiratory Journal, LOFASO et al. [1] report the deleterious effects of oxygen administration in newborn mice. The main message of their work is that repeated brief administration of $100 \%$ oxygen during a critical window, i.e. the first 3 days of life, was associated with a significant decrease in minute ventilation, owing to an increase in absolute total respiratory time and apnoea duration. Most importantly, these adverse effects increased with repeated exposure. The exposure to a lower concentration of oxygen $(30 \%)$ produced comparable effects on breathing pattern. In both situations, recovery was observed after return to normoxia. Before analysing the clinical implications of this work, it is worth discussing the methodology of the study.

\section{THE VALUE OF ANIMAL MODELS}

It is extremely difficult to perform studies in human newborns and infants because of the multitude of ethical issues and the risks associated with unproven therapies in this vulnerable population. In addition, there is an international agreement among paediatricians on the impossibility of performing invasive or potentially dangerous studies in healthy children or children presenting a mild disease [2, 3]. As a consequence, well-conducted animal studies are both necessary and relevant to improve care in infants. A requisite is that the animal model should share the same side-effects and the same period of vulnerability of the organ system as the human child. Mice constitute an excellent model for studying the maturation of respiratory control, as their developmental stage at birth roughly matches that of human pre-term neonates born at 25 weeks gestation [4]. Ventilatory responses to hypoxia and hypercapnia in rats and mice have a similar developmental pattern to the human premature infant.

Whole-body flow barometric plethysmography, as developed and used by LOFASO et al. [1], represents the most suitable

Assistance Publique-Hôpitaux de Paris, Hôpital Armand Trousseau, Paediatric Pulmonary Dept, Université Pierre et Marie Curie, Paris, France.

CORRESPONDENCE: B. Fauroux, Assistance Publique-Hôpitaux de Paris, Hopital Armand Trousseau, Paediatric Pulmonary Dept, Université Pierre et Marie Curie, Paris 6, INSERM UMR-S 719, 26 avenue du Docteur Arnold Netter, 75571 Paris, Cedex 12, France. Fax: 33 144736718. E-mail: brigitte.fauroux@trs.aphp.fr method for studying ventilation in newborn mice, because it is noninvasive and allows the analysis of unrestrained animals $[5,6]$. Indeed, when studying breathing pattern in newborn mice, the method of measure should be validated. The low birth weight $(1.3 \mathrm{~g})$ and tidal volume $\left(3-4 \mu \mathrm{L} \cdot \mathrm{g}^{-1}\right)$ of newborn mice preclude the use of devices that are acceptable for adult mice or larger animals. Moreover, stress, such as restraint, exerts a major influence on ventilation and should be avoided. In these small newborn rodents, metabolism is closely coupled to ventilatory response, which requires simultaneous measurement of temperature and metabolism.

\section{CLINICAL IMPLICATIONS}

The study by LOFASO et al. [1] underlines the deleterious shortterm effects of hyperoxia in newborn mice in inducing hypoventilation and apnoea. Most importantly, they observed that repeated exposure, as frequently encountered in the clinical setting, increasingly depressed breathing. Potential long-term side-effects were not analysed. It is well known that suboptimal environments in the womb and during early neonatal life may alter the development and predispose the individual to permanent, lifelong health problems. Nutrient restriction or overfeeding, maternal stress or exposure to toxins, may be associated with the development of hypertension, diabetes, obesity or altered adrenal function in later life. During development, there are critical periods of vulnerability to suboptimal conditions. Newborn rodents share with humans a critical "window" of vulnerability for the lung and brain tissues at birth. As such, respiratory control impairments at early stages of development compromise brain oxygenation and may cause irreversible motor and cognitive disorders and even structural changes in the specific organ. Newborn rats exposed to chronic hyperoxia have blunted ventilatory responses to hypoxia in adulthood, whereas the same exposure after the neonatal period has little or no effect [7]. Post-natal hyperoxia impairs the response to hypoxia in adulthood, as well as the ability to make plastic changes in respiratory control induced by sustained hypoxia [8]. DAUGER et al. [9] have also shown that hyperoxic exposure during the postnatal period of rapid alveolar multiplication in mice may disturb normal alveolar growth and respiratory mechanics in adulthood.

A factor that could not be analysed in the study by LOFASO et al. [1] was individual susceptibility to post-natal hyperoxia. Bedside data show that some pre-term infants may be predisposed to severe breathing instability, suggesting a role for genetic factors $[10,11]$. Thus, some newborns may be more 
susceptible to a hyperoxic insult than others. This concept of respiratory control immaturity, or injury by pre- or post-natal factors, is nowadays recognised as one of the mechanisms that lead to sudden infant death syndrome (SIDS). Indeed, SIDS is observed with an increased frequency in pre-term babies and abnormalities of breathing, such as partial arousal deficiency or a deficiency in serotonin, have been documented in SIDS victims [12].

What strategy can we now propose to prevent the deleterious effects of oxygen administration in the neonatal intensive care unit? Certainly, the use of the lowest concentration of oxygen is strongly recommended. However, while use of a lower concentration of oxygen may be associated with reduced side-effects of oxygen on other organs, with regard to breathing pattern, comparable depressing ventilatory effects were observed when the animals were exposed to an oxygen concentration of $30 \%$. Perhaps it is necessary to evaluate another therapy which aims to maintain, not depress ventilation. Noninvasive positive pressure ventilation (NPPV), using a pre-set value of inspiratory pressure, may be worth evaluating as a safer technique to prevent hypoxia. Indeed, a recent prospective study compared noninvasive pressure support ventilation with positive end-expiratory pressure, delivered by means of a face mask, with the classical method using a nonrebreather bag-valve mask driven by $15 \mathrm{~L} \cdot \mathrm{min}^{-1}$ oxygen during orotracheal intubation in critically ill adults [13]. NPPV was significantly more effective at reducing arterial oxyhaemoglobin desaturation than the usual method. Premature and term newborns are not adults, but a therapeutic strategy that increases tidal volume and minute ventilation may be associated with less ventilatory depression and potential long-term sideeffects than hyperoxia. Of course, such a treatment should be validated and efficacious without additional oxygen.

The lesson of the work of LOFASO et al. [1] is that therapeutic strategies commonly used in clinical practice should be questioned and, most importantly, rigorously evaluated.

\section{REFERENCES}

1 Lofaso F, Dauger S, Matrot B, Vardon G, Gaultier C, Gallego J. Inhibitory effects of repeated hyperoxia on breathing in newborn mice. Eur Respir J 2007; 29: 18-24.
2 National Health and Medical Research Council (NHMRC). National statement on ethical conduct in research involving humans. Canberra, NHMRC, 1999.

3 Royal College of Paediatrics and Child Health: Ethics Advisory Committee. Guidelines for the ethical conduct of medical research involving children. Arch Dis Child 2002; 82: 177-182.

4 Marret S, Mukendi R, Gadisseux JF, Gressens P, Evrard P. Effect of ibotenate on brain development: an excitotoxic mouse model of microgyria and posthypoxic-like lesions. $J$ Neuropathol Exp Neurol 1995; 54: 358-370.

5 Dauger S, Renolleau S, Vardon G, et al. Ventilatory responses to hypercapnia and hypoxia in Mash-1 heterozygous newborn and adult mice. Pediatr Res 1999; 46: 535-542.

6 Dauger S, Guimiot F, Renolleau S, et al. MASH-1/RET pathway involvement in development of brain stem control of respiratory frequency in newborn mice. Physiol Genomics 2001; 7: 149-157.

7 Carroll JL. Developmental plasticity in respiratory control. J Appl Physiol 2003; 94: 375-389.

8 Bisgard GE, Olson EBJ, Bavis RW, Wenninger J, Nordheim EV, Mitchell GS. Carotid chemoafferent plasticity in adult rats following developmental hyperoxia. Respir Physiol Neurobiol 2005; 145: 3-11.

9 Dauger S, Ferkdadji L, Saumon G, et al. Neonatal exposure to $65 \%$ oxygen durably impairs lung architecture and breathing pattern in adult mice. Chest 2003; 123: 530-538.

10 Bouferrache B, Filtchev S, Leke A, Freville M, Gallego J, Gaultier C. Comparison of the hyperoxic test and the alternate breath test in infants. Am J Respir Crit Care Med 2002; 165: 206-210.

11 Thomas DA, Swaminathan S, Beardsmore CS, et al. Comparison of peripheral chemoreceptor responses in monozygotic and dizygotic twin infants. Am Rev Respir Dis 1993; 148: 1605-1609.

12 Kinney HC, Filiano JJ, White WF. Medullary serotonergic network deficiency in the sudden infant death syndrome: review of a 15-year study of a single dataset. J Neuropathol Exp Neurol 2001; 60: 228-247.

13 Baillard C, Fosse JP, Sebbane M, et al. Noninvasive ventilation improves preoxygenation before intubation of hypoxic patients. Am J Respir Crit Care Med 2006; 174: 171-177. 